\title{
Tomás de Aquino e o problema do Mênon
}

\author{
Anselmo Tadeu Ferreira*
}

Resumo: Procuramos apresentar neste artigo o resultado de uma leitura comparada dos comentários de Tomás de Aquino (1225 - 1274), Roberto Grosseteste (1168 - 1252) e Alberto Magno (1220 - 1280) aos Segundos Analíticos, de Aristóteles. Nossa intenção declarada é avaliar a posição de Tomás de Aquino quanto à teoria aristotélica da ciência em comparação com seus predecessores imediatos na tarefa. Adiantamos que, dada a extensão do trabalho a que nos propomos, este artigo cobre apenas uma pequena parte do mesmo, qual seja, a discussão sobre os preâmbulos da ciência e sobre o chamado "problema do Mênon", temas apresentados por Aristóteles no primeiro capítulo dos Segundos Analíticos.

Palavras-chave: Filosofia medieval. Tomismo. Comentários aristotélicos. Ciência na Idade Média.

\section{Thomas aquinas and the question of Meno}

\begin{abstract}
Our purpose in this article is to present the result of a comparative reading of the commentaries by Thomas Aquinas (1225-1274), Robert Grosseteste (1168 - 1252) and Albert the Great (1220-1280) on Aristotle's Posterior Analytics. We do intend to evaluate the position of Thomas Aquinas about the Aristotelian theory of science comparing it with his immediate predecessors on this task. We put in advance that, due to the extension of the work, this article deals with just a little portion of the text, that is, that part where Aristotle discusses about the prerequisites of science and where the so called "question of Meno" is taken and solved, themes presented in the first chapter of the Posterior Analytics.
\end{abstract}

Keywords: Medieval philosophy. Tomism. Aristotelian commentaries. Science in the Middle Ages.

* Doutor em Filosofia Universidade Estadual de Campinas, professor adjunto na Universidade Federal de Uberlândia (UFU).E-mail: anselmotf@gmail.com 


\section{Thomas D'Aquin et le problème du Mênon}

Resumé: Nous essayons de présenter dans cet article, le résultat d'une lecture comparative des commentaires des Seconds Analitiques d'Aristote, produit par Thomas d'Aquin (1225 - 1274), Robert Grosseteste (1168 - 1252) et Albertus Magnus $(1220-1280)$. Notre intention déclarée est d'évaluer la position de l'Aquin sur la théorie aristotélicienne de la science par rapport à des ses prédécesseurs immédiats dans le travail. Nous prévoyons que, compte tenu de l'ampleur du travail que nous proposons, cet article ne couvre qu'une petite partie de celui-ci, à savoir, la discussion des préambules de la science et de la soi-disant "problème Meno," thèmes présentés par Aristote dans le premier chapitre des Secondes Analytiques.

Mots-clés: Philosophie médiévale. Thomisme. Commentaires aristotéliciennes. La science au Moyen Age.

Tomás de Aquino (1223 - 1274) escreveu comentários sobre uma série de textos aristotélicos. A extensão desse trabalho, como diz Leo Elders, "nos convida a estudar mais de perto a sua posição a respeito da filosofia de Aristóteles". Joseph Owens diz que o papel de Tomás de Aquino como comentador certamente não é "teologicamente neutro como o de acadêmicos modernos, por exemplo Bonitz e Ross" ". A maior parte deste trabalho parece mesmo ter tido relação com sua tarefa principal como teólogo; foram usados como subsídios para a redação da Suma de Teologia e nas controvérsias doutrinárias nas quais se envolveu; por exemplo, o comentário ao De Anima parece ser simultâneo à redação da primeira parte da Suma e o comentário à Ética à Nicômaco à redação da terceira parte assim como os comentários de outros textos, como a Física e a Metafísica, foram realizados no calor da chamada "controvérsia

1 Elders, Leo. "The aristotelian commentaries of St. Thomas Aquinas" em: The review of Metaphysics, 63, September, 2009, 29-53, p. 29.

2 Owens, Joseph. "Aquinas as an Aristotelian commentator", em: Saint Thomas Aquinas on the Existence of God: The Collected Papers of Joseph Owens. Albany, SUNY Press, 1980, p. $1-19$. 
averroísta"3. Quanto aos Segundos Analíticos, parece que Tomás escreveu seu comentário (Expositio Libri Posteriorum Aristotelis ${ }^{4}$ ) atendendo a uma solicitação dos mestres de artes de Paris.

Neste trabalho, procuraremos refletir sobre a atitude de Tomás de Aquino como comentador de Aristóteles, particularmente no que diz respeito ao seu comentário aos Segundos Analíticos. Nosso método consistirá em comparar o texto produzido por Tomás com o de seus contemporâneos, Roberto Grosseteste (+/- 1168-1252) e Alberto Magno (+/-1200-1280) que também produziram comentários sobre este texto. Dada a amplitude desta tarefa, nos limitaremos, neste artigo, a uma pequena parte do texto comentado, qual seja exatamente o primeiro capítulo do livro I dos Segundos Analíticos (71a1 - 71b9), na qual se coloca o problema do conhecimento prévio necessário ao conhecimento científico e onde se insere o chamado "problema do Mênon".

Primeiramente apresentaremos cada um dos comentários em suas linhas gerais e quanto ao ponto específico que é objeto de nossa investigação. Em seguida, faremos uma comparação entre os três trabalhos. Finalmente, a título de conclusão, procuraremos verificar o que é característico da atitude de Tomás de Aquino como comentador de Aristóteles.

À guisa de introdução, seja-nos permitido antes apresentar brevemente a situação dos Segundos Analíticos nesta época em floresceram nossos autores.

\section{Os Segundos Analíticos na Idade Média}

O texto aristotélico, que já era considerado de difícil compreensão por um comentador grego como Temístio, pode ter sido traduzido para o latim, ao menos parcialmente, por Boécio (470 - 526), mas esta tradução,

Ver; Torrell, J-P.(2004), p. $261-289$.

4 Tomás de Aquino. Opera Omnia iussu Leonis XIII P.M. edita, Roma/Paris, Comissio leonina/ Librairie Philosophique J.Vrin, 1989., editio altera retractata, cura et studio Fratrum Praedicatotum, volume I-2. 
se é que existiu, não sobreviveu, pois já no século XII não há sinal dela. Foi, então, traduzido por Tiago de Veneza antes de 1159, uma tradução que se tornou a vulgata quanto a este texto e que foi, por algum tempo, considerada como sendo do próprio Boécio. Pela mesma época uma tradução anônima e, pouco depois, uma versão a partir do texto árabe feita por Gerardo de Cremona, que também traduziu o comentário de Temístio. Finalmente, pela época em que Tomás de Aquino trabalha no texto, circula uma nova versão, feita por Guilherme de Moerbeke a partir do texto de Tiago de Veneza; parece que Tomás a utiliza na maior parte do seu comentário. Todas estas versões encontram-se publicadas hoje no volume 4 do Aristoteles Latinus, editado por L. M. Palluello.

O primeiro autor medieval a referir-se ao texto é João de Salisbury que, no seu Metalogicon, afirma que, por volta de 1159 o texto já era conhecido em Paris, mas quase não havia mestre disposto a ensinar este texto, em parte por causa da sutileza e obscuridade do próprio texto e em parte pela corrupção das cópias e traduções disponíveis.

O primeiro comentário latino medieval propriamente dito foi realizado por Roberto Grosseteste, o maior sábio dos primeiros tempos da universidade de Oxford. Os comentários de Alberto e de Tomás, que atuaram na universidade de Paris, são posteriores e quase contemporâneos entre si, como veremos.

O primeiro capítulo do livro I, como diz Weisheipl ${ }^{5}$, é propedêutico a todo o restante. Aí se coloca o problema da possibilidade do aprendizado, isto é, do próprio conhecimento demonstrativo, já que demonstrar é conhecer algo novo a partir de princípios conhecidos. O conhecimento científico é apresentado, então como o conhecimento de uma conclusão verdadeira, que se dá a partir de premissas verdadeiras, primárias e imediatas, e que são mais conhecidas, anteriores e causas em relação às

5 Weisheipl, James A. Aristotelian Methodology; A Commentary on the Posterior Analytics of Aristotle. River Forest, Ill: Dominican House of Studies, Pontificial Institute of Philosophy, 1958. 
conclusões. Essa definição estrita se defronta com dois problemas iniciais; o primeiro é justamente sobre a possibilidade do aprendizado, que Aristóteles apresenta recorrendo ao "problema do Mênon" e o segundo é como evitar o regresso ad infinitum, se cada proposição conhecida se fundamenta em uma premissa anterior mais conhecida e esta, por sua vez, se fundamenta numa anterior, como evitar que esse processo se estenda ao infinito, o que, em tese, impediria que o processo sequer começasse?

O primeiro destes problemas, que assim podemos resumir: "ou nós já sabemos aquilo que procuramos aprender e, portanto, não aprendemos de fato ou não sabemos o que procuramos e assim, não podemos saber quando o encontramos", é enfrentado e resolvido no primeiro capítulo do livro I. Já no último capítulo do livro II, Aristóteles responde ao segundo problema, indicando que os primeiros princípios indemonstráveis, que são ao mesmo tempo a fonte do conhecimento científico e a base para a sua possiblidade, são adquiridos a partir da experiência sensível.

Vejamos, segundo a ordem cronológica em que foram escritos seus comentários, como cada um dos comentadores trataram deste primeiro problema.

\section{O comentário de Roberto Grosseteste}

Nascido por volta de $1168^{6}$ (a data de nascimento é quase sempre incerta para autores medievais), Roberto Grosseteste morreu como bispo de Lincoln em 1252 depois de, dentre outras coisas, ter escrito várias obras científicas e ter produzido, em alguma época entre 1210 e 1230, o primeiro comentário latino dos Segundos Analíticos ${ }^{7}$. Como tinha fami-

6 Cf. McEvoy James. Robert Grosseteste, New York, Oford University Press, 2000 (Great Medieval Thinkers).

7 Robertus Grosseteste,. Commentarius in Posteriorum Analyticorum Libros, Firenze: L.S. Olschki, 1981. Edição crítica e introdução de Pietro Rossi. A datação da obra é detalhadamente considerada pelo editor, mas a conclusão só é certa para a data limite de 1230 . 
liaridade com a língua grega, parece ter se servido de textos originais, além das traduções latinas tanto do texto aristotélico como de alguns dos comentadores árabes.

O comentário de Roberto Grosseteste, embora não divida o texto tão detalhadamente como fará Tomás, também comenta o texto a partir de uma divisão que respeita a ordem do próprio texto sem muitas interferências explícitas diretas. A clareza do texto foi responsável pelo seu sucesso. O texto se compõe de 19 capítulos para o livro I e 6 capítulos para o livro II dos Segundos Analíticos.

A realização de Grosseteste é tanto mais valiosa quanto seja ele o primeiro a satisfazer a necessidade de compreensão desta difícil obra de Aristóteles, num contexto em que se tornavam conhecidas as obras do Organon, que compunham a então chamada Lógica Nova, isto é, os Segundos Analíticos, os Tópicos e as Refutações Sofísticas principalmente. Pelo testemunho de João de Salisbury, em seu Metalogicon ${ }^{8}$, sabemos que, por volta de 1159 toda a obra lógica de Aristóteles estava disponível aos círculos cultos da latinidade ocidental, contudo, seja pela dificuldade própria do texto, seja pelas traduções latinas imprecisas, os Segundos Analíticos eram, ainda no final do século XII e começo do XIII, de difícil assimilação pelos interessados ${ }^{9}$. Grosseteste escreveu uma obra de sucesso que, justamente, buscava atender a essa necessidade. $\mathrm{O}$ ambiente de Oxford, onde ele floresceu, era aberto, como dissemos aos textos da Lógica Nova, segundo o testemunho de Rogério Bacon, que cita dois mestres anteriores, Edmundo e Hugo, como comentadores pioneiros destas obras ${ }^{10}$.

Ao comentar os Segundos Analíticos, Roberto se apoia certamente em uma tradição interpretativa cuja transmissão direta está perdida. Ele cita expressamente em dois lugares os expositores ou exponentes, o que

\footnotetext{
8 Citado por Pietro Rossi em Robertus Grosseteste (1981), Introdução, p. 23.

9 Na verdade, a dificuldade do texto não diminuiu com os séculos!

10 Robertus Grosseteste, 1981, p. 14
} 
indica comentadores do texto ${ }^{11}$, não tradutores. Nesta tradição certamente devem ser considerados o comentário de Temístio, citado quatro vezes por Roberto; fragmentos, ao menos, do comentário de Alexandre de Afrodísia, que se encontravam traduzidos à época e o comentário de João Filopono, que, embora não seja citado, a leitura de certas passagens do texto de Roberto parece indicar sua dependência quanto a esta fonte ${ }^{12}$.

Essas considerações permitem a Pietro Rossi estabelecer como data para a redação do comentário grossatestiano alguma época entre 1210 e 1230 (a data ante quem é inferida da total ausência de referência, direta ou indireta, a Averroes). Restam conhecidos desta obra 32 manuscritos e dez edições, que foram a base para a edição do texto crítico de Rossi ${ }^{13}$.

O comentário de Roberto se abre com a seguinte sentença: "A intenção de Aristóteles neste livro é investigar e manifestar as partes essenciais da demonstração; por esta razão o gênero sujeito na ciência tratada neste livro é a demonstração." 14 Já nesta frase de abertura se manifesta a concepção adotada por Roberto segundo a qual ciência é simplesmente o assunto tratado em um livro ("a ciência tratada neste livro"). Nessa concepção, uma ciência não é necessariamente considerada segundo a unidade do assunto, mas como um encadeamento de proposições; tal encadeamento, contudo, não é arbitrário, é comandado pelo genus subiectum (gênero sujeito), que neste caso é a demonstração.

Essa concepção determina a própria forma do comentário de Roberto que se apresenta como uma sucessão de conclusões, isto é, proposições que se sustentam a partir de outras proposições anteriormente conhecidas. Assim, a própria ciência da demonstração é apresentada de acordo

$11 \quad$ Livro I,1, $94-96$ e livro I,4, $111-112$

12 Pietro Rossi, na introdução, indica o Livro I,7, 167-168, que dependeria do comentário de Filopono, p. 109 - 110 na edição de M. Wallies.

13 Robertus Grosseteste, 1981, p. 32 - 33

14 "Intentio Aristotelis in hoc libro est investigare et manifestareessentialia demonstrationis; quapropter in scientia tradita in isto libro est demonstratio genus subiectum." (I,1,1-2). 
com a forma da ciência demonstrativa apresentada por Aristóteles nos Segundos Analíticos.

A primeira conclusão desta ciência é a seguinte: "a ciência demonstrativa se dá a partir do que é verdadeiro, primeiro e imediato, e anterior, mais conhecido e causa da conclusão". ${ }^{15}$ Essa sentença, célebre em si mesma, encontra-se no princípio do texto aristotélico (71b 19 segundo a numeração Bekker). Seguem-se então, mais 31 conclusões referentes ao livro primeiro e outras 32 referentes ao livro segundo, ou seja, a exposição ou comentário dos Segundos Analíticos por Roberto Grosseteste se dá na forma de um encadeamento de 64 conclusões. Essa forma mesma de apresentação configura-se como a aplicação do que Aristóteles considera ser a forma de uma ciência demonstrativa, na qual cada conclusão universal, necessária e verdadeira se apoia em premissas ou princípios do mesmo tipo, derivadas precipuamente na forma do silogismo em BARBARA.

Vemos então que o primeiro problema que se coloca nos Segundos Analíticos é o problema do conhecimento prévio, necessário ao conhecimento de cada conclusão. É neste contexto que se apresenta o "problema do Mênon”. Vejamos como Grosseteste apresenta o problema e a sua solução por Aristóteles.

No primeiro capítulo de seu comentário, no qual não deixa explícita nenhuma divisão exaustiva do texto como um todo nem apresenta um esquema geral no qual se enquadraria a obra em questão, Roberto Grosseteste trata exatamente do capítulo primeiro dos Segundos Analíticos (71a 1 - 71b 9). O tema do livro, diz ele, é a demonstração. Como a demonstração é o silogismo que produz ciência, é necessário supor que a ciência seja possível. Ora, nenhum artífice tem a obrigação de estabelecer o sujeito de sua arte nem se trata de transgressão supor algo sem uma justificativa completa, mas como, neste caso, há contradição entre os filósofos, foi necessário que Aristóteles, antes de começar a tratar de

15 "Scientia demonstrativa est ex veris et primis et immediatis et prioribus et notiribus et causis conclusionis" 
seu assunto abordasse a questão sobre o modo pelo qual é possível saber algo, ensinar e aprender esse algo. A contradição a que ele se refere é a seguinte: os acadêmicos dizem que nada podemos conhecer com certeza e os platônicos dizem que, ou nada aprendemos ou só aprendemos o que já sabíamos.

Essa proposição resume, segundo Grosseteste, o que Aristóteles procura fazer no referido capítulo, o qual versa sobre a explicação da dita proposição. Nesta explicação Aristóteles mostra como chegamos ao conhecimento científico por demonstração, que se dá a partir de conhecimento prévio e mostra também de que tipo de conhecimento prévio se trata bem como divide os modos de conhecer previamente algo.

Ao comentar esta frase, que é a frase de abertura dos Segundos Analíticos, Grosseteste faz a seguinte observação em primeira pessoa:

digo que a ciência dos princípios não é adquirida por ensinamento, pois não ensinamos nem aprendemos senão aquilo que, quando o concebemos primeiramente, para nós parece duvidoso ou mesmo falso e depois da dúvida e da opinião contrária se manifesta a nós a sua verdade (GROSSETESTE, 1981, p. 94).

Há aqui uma alusão certamente à noção de que os princípios são auto evidentes, noção muito importante no esquema aristotélico. Em seguida, complementa:

não chamo ensinamento somente aquilo que ouvimos da boca dos mestres, mas também considero a escritura no lugar do mestre; e para dizer com mais verdade, nem aquele que faz um som exteriormente ensina nem a escritura vista exteriormente ensina, mas estes dois apenas movem e excitam; mas o verdadeiro mestre é aquele que, no interior da mente ilumina e mostra a verdade (GROSSETESTE, 1981, p. 94).

Trata-se de uma curiosa interpretação agostiniana de uma noção aristotélica. Assim, o conhecimento dos princípios, que é auto evidente 
para Aristóteles é, para Grosseteste, resultado da iluminação divina ou em virtude do mestre interior.

Após essa observação pessoal, Grosseteste volta ao texto. Aristóteles, segundo ele, prova aquela proposição inicial primeiramente por indução, já que trata-se de fato estabelecido que as ciências matemáticas e as mecânicas a ela subalternadas, como também os silogismos em geral, as induções e os entimemas, todos estes partem de algo conhecido para provar o desconhecido. Em seguida prossegue, a modo de divisão, a explanação a respeito do conhecimento prévio.

O conhecimento prévio pode ser de dois tipos: sobre o ser, relacionado aos princípios e sobre o que é dito, relacionado à propriedade. Estes dois tipos se combinam em um terceiro que é o sujeito. O exemplo da propriedade é o triângulo, o primeiro objeto de pesquisa na geometria, o exemplo de sujeito é a unidade, o primeiro sujeito de conclusão na aritmética; de fato, que a proposição "a unidade é numerada por outro número" é falsa se prova por redução ao absurdo, isto é, diretamente se prova que o contrário disto resulta em absurdo e indiretamente o que é a unidade; ora, na prova por redução ao absurdo está assumido o princípio de contradição segundo o qual "do que quer que seja, a afirmação ou a negação é verdadeira" ${ }^{16}$. Tal princípio é o exemplo do primeiro tipo de conhecimento prévio, o qual é autoevidente. O princípio, sabemos que é verdadeiro, a propriedade sabemos o que significa e o sujeito sabemos tanto que é verdadeiro como o que significa. Ficam assim estabelecidos os três tipos de conhecimento prévio considerados por Aristóteles.

Em seguida, sempre acompanhando o texto, Grosseteste apresenta outra divisão do conhecimento prévio, aquele que é anterior quanto ao tempo e o que é anterior apenas logicamente, mas simultâneo quanto ao tempo. Para exemplificar essa divisão, ele apresenta o mesmo exemplo que se encontra no texto aristotélico, que é o seguinte silogismo "todo triângulo tem três ângulos iguais a dois retos, esta figura inscrita no se-

16 GROSSETESTE, 1981, p. 95. 
micírculo é um triângulo; logo, esta figura inscrita no semicírculo tem três ângulos iguais a dois retos" ${ }^{\prime 17}$. Neste silogismo, a premissa maior é conhecida previamente quanto ao tempo, mas a premissa menor, apesar de logicamente anterior à conclusão, é conhecida simultaneamente a esta, pois quando sei, pelo sentido, que esta figura é um triângulo, imediatamente sei que tem ângulos iguais a dois retos, em virtude daquele conhecimento prévio. Ora, esse exemplo ilustra à perfeição a distinção que Aristóteles pretende estabelecer entre conhecer universalmente e conhecer em si. Daí a conclusão de que tudo que se aprende por ensinamento, já era, de algum modo conhecido (universalmente), mas de algum modo desconhecido (em si).

Essas considerações serão suficientes para resolver o "problema" do Mênon, assim por ele apresentado:

o que alguém aprende ou sabia anteriormente ou não; se sabia anteriormente, então não aprende, logo o que alguém aprende, não aprende. Mas se não sabia anteriormente, quando isso ocorrer a ele, não sabe se é o que buscava ou não. E Platão acrescenta o exemplo do senhor (paterfamilias) que procura um escravo fugitivo, o qual se não fosse conhecido daquele que o procura, mesmo que o encontrasse na rua, não o reconheceria mais do que a qualquer outro" (GROSSETESTE, 1981, p. 97).

Na resposta a essa objeção, segundo Grosseteste, Aristóteles conclui que:

aquele que aprende algo nem previamente sabe aquilo pura e simplesmente nem ignora completamente, mas conhece sob um certo aspecto e, sob este aspecto não aprende, mas na medida em que conhece sob esse aspecto é que conhece sobre o que era em si simplesmente ignorado que é aquilo que procurava saber (GROSSETESTE, 1981, p. 98).

17 GROSSETESTE, 1981, p. 95. 
Assim se conclui o primeiro capítulo do comentário de Grosseteste, no qual ele trata exatamente do conteúdo do primeiro capítulo dos $\mathrm{Se}$ gundos Analíticos de Aristóteles, com apenas uma pequena observação pessoal, além de uma explicação de que "estas palavras - previamente conhecido no universal e ignorado em própria pessoa - não são de Aristóteles mas de seus comentadores".

\section{O comentário de Alberto Magno}

Alberto Magno, nascido por volta do ano $1200^{18}$, foi o primeiro dominicano alemão a obter o título de mestre de teologia em Paris. Partiu dele também a iniciativa de, 10 anos depois de ter ensinado em Paris e já exercendo funções de direção na Ordem Dominicana, designar Tomás de Aquino para fazer estudos em Paris a fim de posteriormente ocupar uma das cadeiras de teologia dos dominicanos naquela universidade.

O "projeto aristotélico" de Alberto é bem mais amplo e ambicioso do que o de Tomás ${ }^{19}$. De fato, o seu propósito era o de reescrever as obras do Filósofo, expondo-as, corrigindo-as e emendando-as onde fosse o caso a fim de transmitir aos latinos todo o conjunto da ciência contida nessas obras, tendo, para isto, escrito comentários ou paráfrases de virtualmente todas elas, além de outras obras pseudo aristotélicas como o Liber De Causis, que ele já sabia não ser de Aristóteles ${ }^{20}$. De especial interesse para Alberto eram as obras sobre ciência natural, as quais Tomás não deu muita atenção. Era sua convicção que todas as ciências são necessárias para quem quiser entender a Teologia e que a verdade das ciências na-

18 Os dados biográficos aqui apresentados foram retirados do artigo de Weisheipl, 1980. p. $13-52$.

19 Weishepl refere que um Roger Bacon enciumado reclama de que "hoje em dia a filosofia é ensinada aos vulgos em latim e o autor desta empreitada ainda é louvado indecentemente sendo equiparado aos grandes Aristóteles, Avicena e Averroes, estando ele ainda vivo". (WEISHEIPL, 1980, p. 14).

20 WEISHEIPL, 1980, p. 14. 
turais não pode contradizer as verdades reveladas, convicção que seria compartilhada por Tomás.

O comentário das obras lógicas de Aristóteles foi executado paralelamente ao comentário das obras científicas e políticas. Quanto ao comentário aos Segundos Analíticos, Weishepl acha provável que Alberto tenha trabalhado nele no período de lazer que ele teve quando visitou a cúria romana a fim de pedir dispensa de seu cargo de bispo, o que seria dezenove meses entre os anos de 1261 e $1263^{21}$. Não fazia parte das atribuições de Alberto, como mestre de teologia, o ensino destas obras; a bem da verdade, a essa altura, meados do século XIII, o corpus aristotélico ainda estava sendo absorvido pelo mundo da alta cultura da latinidade ocidental e, em Paris, boa parte dessas obras tinham o seu ensino público proibido pelas autoridades eclesiásticas, temerosas das possíveis divergências entre a doutrina de Aristóteles com a doutrina cristã. Portanto, esses comentários não foram frutos de lições ou cursos ministrados por ele, nem se destinavam a isso; não é crível, todavia que se tratasse apenas de um hobby particular e por isso talvez se destinassem à discussão com um público mais avançado.

Homem de curiosidade voraz, Alberto aproveitava a sua vida de viajante e de homem de ação, (além de ter sido provincial da Ordem Dominicana, chegou a ser bispo na Alemanha) para inquirir sobre todos os assuntos em que se via envolvido e consultar todos os livros possíveis onde quer que se encontrasse. Talvez em razão dessa sua curiosidade enciclopédica, os seus comentários aristotélicos também contenham esse estilo enciclopédico. De tal modo que Ashley os classifica mais como paráfrases ao estilo aviceniano do que como um comentário ao estilo parisiense ${ }^{22}$. Essa é de, fato, a diferença mais notável entre os comentários de Alberto comparativamente aos de Roberto e de Tomás.

$21 \quad$ WEISHEIPL, 1980, p. 39.

22 Ashley, Benedict. "St. Albert and the nature of natural sciences", em: Weisheipl, J. (ed.) (1980), p. 79, nota 31. 
No comentário de Alberto, o texto aristotélico é dividido também seguindo rigorosamente a ordem do texto. Há algumas divisões maiores, chamadas de Tratados, cada um deles subdividido em capítulos; cada capítulo, por sua vez, lida com uma porção do texto. O objeto do comentário é o texto aristotélico, mas Alberto faz amplas digressões e o resultado é um texto não tão claro quanto o de Roberto ou o de Tomás, mas muito mais erudito e, em nossa opinião, de leitura mais agradável.

O capítulo 1 do livro 1 dos Segundos Analíticos é objeto do tratado primeiro, que tem como título: "Do que é preciso ter antes da ciência e sobre o modo universal de saber" 23 , isto é, o tema do tratado é o conhecimento prévio necessário ao conhecimento científico. No tratamento do texto, Alberto se estende bem mais do que o comentário de Grosseteste: ao invés de um único capítulo, ele precisa de cinco até chegar na dúvida do Mênon e sua solução, tendo antes passado pelos preâmbulos da ciência (capítulo 1), pela prova de Avicena e Al Gazali de que os Segundos Analíticos seguem-se imediatamente aos Primeiros Analíticos (capítulo 2), pela tese segundo a qual a ciência intelectiva se dá a partir de conhecimento preexistente (capítulo 3), pela discriminação dos tipos de conhecimento prévio, precipuamente na ciência demonstrativa (capítulo 4) e, finalmente, pela abordagem do conhecimento prévio das conclusões (capítulo 5). Em suma, as meras 43 linhas do texto aristotélico renderam dezenove páginas no comentário de Alberto na edição Borgnet.

Apesar de conter muitas digressões e de introduzir muitos outros autores, percebemos que, ao menos quanto a essa parte que é objeto de nossa análise, Alberto segue bem de perto o texto aristotélico. Contando os dois primeiros capítulos como introdutórios, nos quais ele se deleita em esbanjar sua erudição (citando Avicena, Algazali, Boécio, Zenon, Empédocles e as obras aristotélicas De Anima, Ética, Metafísica), ele realmente entra no assunto do livro somente a partir do capítulo terceiro.

23 Em latim: "De his quae praemitti habent ante scientiam, et de universali sciendi modo" 
O primeiro tema a ser tratado é o conhecimento prévio. Uma vez que a sentença de abertura dos Segundos Analíticos é "todo ensinamento e todo aprendizado intelectual se dá a partir de conhecimento prévio", todos os capítulos seguintes do Tratado I, a começar pelo capítulo 3, serão dedicados a este tema, seguindo a ordem de apresentação do próprio Aristóteles, ou seja, em primeiro lugar discriminando os dois (ou três) tipos de conhecimento prévio (do que é, do que é dito e de uma combinação de ambos), assunto do capítulo 4 e, em seguida, determinando sobre o conhecimento da conclusão de um silogismo; esta é, de fato conhecida sob certo aspecto, mas sob certo aspecto ignorada, assunto do capítulo 5. É neste contexto que surge o "problema do Mênon".

Alberto dá prova de conhecer com exatidão o problema de que se fala neste ponto. Ele diz que Mênon era um discípulo de Platão a quem foi dedicada uma resposta à questão se a virtude pode ser ensinada. A resposta platônica, segundo ele, é que a virtude não pode ser ensinada, mas apenas dada por Deus àqueles que voltam-se para si mesmos e a encontram em sua alma. Acrescenta que, com essa resposta concordam Agostinho, Boécio e, talvez, também Gregório de Nyssa. Está claro que Alberto não confrontará, ao menos diretamente, autoridades tão respeitáveis. Mas ele também dá sinal de não conhecer o diálogo platônico em primeira mão, pois atribui a Agostinho o exemplo do senhor que, ao buscar um escravo fugitivo que não conhece não teria como reconhecê-lo se o encontrasse; ora, este exemplo encontra-se no próprio texto platônico.

O problema é discutido segundo a ordem que aparece no texto de Aristóteles. Assim, em primeiro lugar, o problema é posto como argumento na forma de redução ao absurdo: antes que se conheça a conclusão de um silogismo, de certo modo a conhecemos previamente, mas de certo modo, não a conhecemos. Se isso não fosse possível, darse-ia a ambiguidade do Mênon, que é a seguinte: ou nada se aprende ou se aprende o que já era sabido. Em seguida, é impugnada uma solução que consistia em enfraquecer a universalidade da conclusão e, enfim, se afirma que nada proíbe que aquilo que alguém aprende já 
saiba previamente de certo modo, mas ignore de certo modo (que é a solução aristotélica, resumidamente).

Depois de explicar essa passagem nesta ordem, e certamente considerando que Aristóteles lidou sumariamente com o problema, Alberto ainda acrescenta um capítulo, o sexto do Tratado I, intitulado "Sobre a dúvida do Mênon e sua solução" onde, mais uma vez esbanjando erudição, Alberto nos ensina que

Aqui, para que mais perfeitamente seja o ensinamento deve-se interpor a dúvida do Mênon e resolvê-la, ainda que isto pareça pertencer mais à metafísica. Saibas que a dúvida do Mênon, se funda na antiquíssima opinião de Anaxágoras sobre a latência das formas, segundo a qual todas as formas que devem ser concebidas já estão interiormente naquele que há de concebê-las, e pelo movimento a matéria deve depurá-las e fazê-las aparecer, tal como a pedra preciosa, que precisa ser polida, etc. (MAGNO, 1890, p. 18).

Em seguida apresenta cinco argumentos a favor da posição platônica exposta no Mênon e a solução dos peripatéticos e de Boécio para as mesmas. Nestes argumentos, o vemos mobilizar todo o seu conhecimento das fontes da filosofia grega e dos latinos. Por interessante que sejam essas considerações, seja-nos permitido ultrapassá-las, fogem ao escopo de nosso artigo. Encerramos assim, a exposição de Alberto sobre o capítulo 1 dos Segundos Analíticos.

\section{O comentário de Tomás de Aquino}

Quando Alberto esteve na cúria romana, entre 1261 e 1263, ele se encontrou com o seu antigo assistente e amigo Tomás de Aquino ${ }^{24}$. Por meio deste, deve ter ficado sabendo sobre a nova tradução da Metafísica por Moerbeke. Podem também ter conversado a respeito dos Segundos

24 WEISHEPL, 1980, p. 38 - 39. 
Analíticos, no qual Alberto iria trabalhar por aquela época e sobre o qual Tomás também se debruçaria alguns anos depois. A Expositio de Tomás de Aquino, no entanto, seria escrita na forma de um comentário literal, isto é, um comentário linha por linha, e não uma paráfrase recheada de citações eruditas como a do mestre. $\mathrm{O}$ trabalho foi realizado a partir da tradução latina de Tiago de Veneza até o capítulo 15 do livro I (79b23 na numeração Bekker), ponto em que Tomás, por alguma razão, parece adotar a revisão do texto de Tiago feita por Guilherme de Moerbeke ${ }^{25}$. Antes de proceder ao comentário de cada passagem "atômica", Tomás apresenta sempre uma visão sintética do conjunto do capítulo e do conjunto de capítulos em que um tema é tratado. Trata-se de uma espécie de análise estrutural do texto ${ }^{26}$.

As versões latinas do texto aristotélico de que Tomás dispõe, visto que ele não lê grego, são sintéticas ao extremo e muito elípticas, com muitas passagens quase criptográficas, é de fato digno de nota que Tomás tenha conseguido extrair desses escritos um sentido muito parecido com interpretações modernas, feitas por estudiosos com acesso ao texto grego, como por exemplo, os comentários de Ross ${ }^{27}$ e o de Porchat ${ }^{28}$ sobre os Segundos Analíticos ${ }^{29}$.

O comentário de Tomás de Aquino, escrito por volta de 1272, como dissemos acima, parece atender ao pedido dos mestres da faculdade de

${ }_{25}$ AQUINO ,1989, Introdução p. XIV

26 Weijers (2002) chama esse tipo de comentário de "comentário parisiense" e os comentários aristotélicos de Tomás de Aquino são seu melhor exemplo.

27 Ross, (2000).

28 Pereira, Oswaldo Porchat. (2001).

29 Apesar de considerados bastante claros e originais em sua época, os comentários aristotélicos de Tomás de Aquino foram colocados sob suspeição por modernos estudiosos de Aristóteles quanto à sua fidelidade ao pensamento do Estagirita. Leo Elders (2009, p. 29) cita Joseph Owens, Harry Jaffa e M.-D. Jordan como defensores da tese segundo a qual há um vício nos comentários, os pressupostos da doutrina cristã aos quais têm de se adequar, que os tornam inúteis para uma exegese histórico-crítica da obra de Aristóteles. 
artes e é, de fato, tipicamente "parisiense" 30 . Nele, apresenta-se uma visão de conjunto do texto a ser comentado, explicita-se as suas divisões internas e, em seguida, procede-se a um comentário linha por linha, com poucas e bem marcadas intervenções do comentador.

O mesmo capítulo 1 do livro de Aristóteles, de 71a 1 até $71 \mathrm{~b} 8$, segundo a numeração Bekker, é tratado nos três primeiros capítulos do comentário tomista.

O primeiro capítulo é, na verdade, um proêmio, no qual ele faz uma apresentação da estrutura da lógica, relacionando as suas partes com as operações do espírito ou atos da razão e com as obras que compõem o Organon. No final deste capítulo, ele trata da noção de que todo conhecimento intelectivo provém de algum conhecimento previamente existente em nós. Esse proêmio é talvez a mais clara demonstração da influência de Alberto sobre Tomás, tanto quanto ao estilo (de fato Tomás mobiliza o seu conhecimento para dar uma visão de conjunto sobre a obra) quanto com relação ao conteúdo (também Alberto relaciona as partes da lógica com as operações do espírito).

No segundo capítulo, Tomás expõe sobre o modo e a ordem necessária para que o conhecimento prévio nos leve à aquisição de ciência, segundo a ordem do texto aristotélico.

No terceiro capítulo, Tomás aborda o tema do conhecimento prévio da conclusão de um silogismo. Neste ponto, ele apresenta a ideia aristotélica segundo a qual a conclusão de um silogismo ou de uma indução já é, de certo modo conhecida por nós antes que a saibamos de fato, mas de certo modo é desconhecida, isto é, ela não é conhecida pura e simplesmente mas apenas sob certo aspecto. E para corroborar essa ideia, apresenta-se o "falso" dilema do Mênon.

Em uma intervenção nesse capítulo, Tomás diz:

$30 \quad$ A existência de um exemplar, a partir do qual foram produzidos os manuscritos atualmente conhecidos é o sinal para que Olga Weijers (2002), assim o classifique. 
como já foi mostrado, é preciso conhecer previamente os princípios da conclusão; ora, os princípios se relacionam à conclusão assim como, na natureza, as causas ativas relacionam-se aos seus efeitos (assim, no livro II da Física, as proposições do silogismo são postas no gênero das causas eficientes); ora, o efeito, antes que se produza em ato, certamente preexiste virtualmente nas causas ativas, mas não em ato, o que é ser pura e simplesmente; do mesmo modo antes que se deduza a conclusão a partir dos princípios da demonstração, a conclusão é previamente conhecida nos próprios princípios virtualmente, mas não em ato, assim preexiste, com efeito, neles. E assim, fica patente que não é conhecida previamente pura e simplesmente, mas sob certo aspecto (AQUINO, 1989, p. $14-15$ ).

Sem aludir ainda ao intelecto (o que ele fará mais tarde) nem à iluminação divina (o que ele nunca fará neste livro), Tomás dá uma explicação que resolve o dilema do Mênon em termos puramente aristotélicos: em certo sentido já conhecemos previamente o que procuramos, mas não em sentido estrito. Essa é a natureza do conhecimento demonstrativo, isto é, científico segundo Aristóteles: a partir de certos princípios conhecidos de modo não científico, é possível derivar, silogisticamente, todo o edifício de conhecimentos científicos que podemos almejar atingir.

\section{Os Segundos Analíticos segundo Roberto, Alberto e Tomás}

Façamos agora algumas observações comparando os três comentários quanto ao texto aqui considerado. No quadro a seguir, apresentamos como o texto aristotélico é dividido e apresentado em cada um dos comentários.

\section{LIVRO 1}

\begin{tabular}{|c|c|c|c|}
\hline Aristóteles & Tomás & Roberto & Alberto \\
\hline $1-71 a 1$ & $1-3$ & 1 & Tratado 1, 1-6 \\
\hline $2-71 b 10$ & $4-6$ & 2 & Tratado $2,1-5$ \\
\hline $3-72 b 5$ & $7-8$ & 3 & Tratado 2, 6 \\
\hline
\end{tabular}




\begin{tabular}{|c|c|c|c|}
\hline Aristóteles & Tomás & Roberto & Alberto \\
\hline $4-73 a 21$ & $9-11$ & 4 & $\begin{array}{l}\text { Tratado 2, } \\
7-12\end{array}$ \\
\hline $5-74 a 5$ & 12 & 5 & $\begin{array}{l}\text { Tratado 2, } \\
13-14\end{array}$ \\
\hline $6-74 b 5$ & $13-14$ & 6 & $\begin{array}{l}\text { Tratado } 2,15 \\
\text { e } 17\end{array}$ \\
\hline $7-75 a 38$ & 15 & 7 & $\begin{array}{l}\text { Tratado 2, } 16 \\
\text { e } 18\end{array}$ \\
\hline $8-75 b 21$ & 16 & 7 & Tratado 2, 17 \\
\hline $9-75 b 37$ & $17(75 b 37-76 a 25)$ & 8 & Tratado 2,18 \\
\hline $10-76 a 31$ & $17-19$ (76a 26 - 77a9) & 8 & Tratado 2,18 \\
\hline $11-77 a 5$ & $\begin{array}{l}19-20(77 \mathrm{a} 10-77 \mathrm{a} \\
35)\end{array}$ & $\begin{array}{l}9-10(77 a 10-77 a \\
35)\end{array}$ & Tratado $3,1-4$ \\
\hline $12-77 a 36$ & $21-22$ & 11 & Tratado 3, 5 \\
\hline $13-78 \mathrm{a} 21$ & $23-25$ & 12 & Tratado 3, 6-7 \\
\hline $14-79 a 17$ & 26 & 13 & Tratado 3, 8 \\
\hline $15-79 a 33$ & 26 & 14 & Tratado 3, 8 \\
\hline $16-79 b 23$ & $27-28$ & 14 & Tratado 4, 1-3 \\
\hline $17-80 b 16$ & 29 & 14 & Tratado 4, 4-6 \\
\hline $18-81 a 37$ & 30 & 14 & Tratado 4, 7-8 \\
\hline $19-81 b 10$ & 31 & 15 & Tratado 4, 9 \\
\hline $20-82 a 21$ & 32 & 15 & Tratado 4, 10 \\
\hline $21-82 a 36$ & 32 & 15 & Tratado 4,10 \\
\hline $22-82 b 37$ & $33-35$ & 15 & $\begin{array}{l}\text { Tratado } 4, \\
11-13\end{array}$ \\
\hline $23-84 b 5$ & 36 & 16 & $\begin{array}{l}\text { Tratado } 4, \\
14-15\end{array}$ \\
\hline $24-85 a 14$ & $37-38$ & 17 & Tratado 5, 1-2 \\
\hline $25-86 a 31$ & 39 & 17 & Tratado 5, 3 \\
\hline $26-87 a 1$ & 40 & 17 & Tratado 5, 4 \\
\hline $27-87 a 31$ & 41 & 17 & Tratado 5, 6 \\
\hline
\end{tabular}




\begin{tabular}{|l|l|l|l|}
\hline $28-87 \mathrm{a} 38$ & 41 & 18 & \multicolumn{1}{|c|}{ Tratado 5, 6 } \\
\hline Aristóteles & \multicolumn{1}{|c|}{ Tomás } & \multicolumn{1}{c|}{ Roberto } & \multicolumn{1}{|c|}{ Alberto } \\
\hline $29-89 \mathrm{~b} 5$ & 41 & 18 & Tratado 5, 6 \\
\hline $30-87 \mathrm{~b} 19$ & 42 & 18 & Tratado 5, 7 \\
\hline $31-87 \mathrm{~b} 28$ & 42 & 18 & Tratado 5, 7 \\
\hline $32-88 \mathrm{a} 17$ & 43 & 18 & Tratado 5, 8 \\
\hline $33-88 \mathrm{~b} 30$ & 44 & 19 & $\begin{array}{l}\text { Tratado 5, } \\
9-10\end{array}$ \\
\hline $34-89 \mathrm{~b} 10$ & 44 & 19 & $\begin{array}{l}\text { Tratado 5, } \\
9-10\end{array}$ \\
\hline fim - 89b 20 & $1-44$ & $1-19$ & $\begin{array}{l}\text { T1 - T5 (56 } \\
\text { capítulos) }\end{array}$ \\
\hline
\end{tabular}

\section{LIVRO 2}

\begin{tabular}{|c|c|c|c|}
\hline Aristóteles & Tomás & Roberto & Alberto \\
\hline $1-89 b 23$ & 1 & 1 & Tratado $1,1-3$ \\
\hline $2-89 b 36$ & 1 & 1 & Tratado 2, 1-2 \\
\hline 3 - 90a 35 & 2 & 2 & \\
\hline $4-91 a 12$ & 3 & 2 & \\
\hline $5-91 b 12$ & 4 & 2 & \\
\hline $6-92 a 6$ & 5 & 2 & \\
\hline $7-92 a 34$ & 6 & 2 & \\
\hline $8-93 a 1$ & 7 & 2 & \\
\hline $9-93 b 21$ & 8 & 2 & \\
\hline $10-93 b 29$ & 8 & 2 & \\
\hline $11-94 a 20$ & 9 & 3 & Tratado $3,1-5$ \\
\hline $12-95 a 10$ & $10-12$ & 3 & Tratado 3, 6-7 \\
\hline 13 - 96a 20 & $13-16$ & 4 & Tratado $4,1-5$ \\
\hline $14-98 a 1$ & 17 & 4 & Tratado 4, 6 \\
\hline 15 - 98a 24 & 17 & 4 & Tratado 4, 6 \\
\hline $16-98 a 35$ & 18 & 5 & Tratado $4,7-8$ \\
\hline
\end{tabular}




\begin{tabular}{|c|c|c|c|}
\hline $17-99 a 1$ & 19 & 5 & Tratado 4,9 \\
\hline $18-99 b 9$ & 19 & 5 & Tratado 4, 9 \\
\hline Aristóteles & Tomás & Roberto & Alberto \\
\hline $19-99 b 15$ & 20 & 6 & Tratado $5,1-2$ \\
\hline $\begin{array}{l}\text { Fim - 100b } \\
17\end{array}$ & 20 capítulos & & \\
\hline
\end{tabular}

Embora cada um tenha uma maneira peculiar de divisão do texto, o quadro nos mostra que, na maior parte, eles mantém uma certa semelhança nas marcas de divisão do texto. O comentário de Roberto tem uma tendência a agrupar vários capítulos em cada capítulo de sua exposição, os 34 capítulos do livro I rendem 19 capítulos do comentário e os 19 do livro II são reduzidos a apenas 6 . Ao contrário, Alberto e Tomás tendem a estender a exposição de um único capítulo por vários capítulos. Assim, os 34 capítulos do livro I rendem 56 capítulos e os 19 do livro II rendem 23 capítulos no comentário de Alberto, embora ele agrupe os capítulos em Tratados ( 5 para cada livro). Tomás acompanha a tendência de Alberto e estende o comentário dos 34 capítulos do livro I por 44 capítulos e os 19 do livro II por 20. Vemos por essa comparação como Tomás parece também combinar os dois métodos de exposição quanto às divisões maiores do texto. Quanto às divisões atômicas, no entanto, o trabalho de Tomás é sem precedentes, na medida em que ele faz uma exposição do texto linha por linha e é a tal ponto rigoroso neste escrutínio que é quase possível reconstruir a versão do texto por ele utilizada a partir de suas citações ou lemas na divisio textus. Embora, seja dito, os três se preocupam em citar o texto, segundo o modelo "da parte que vai de... a ... Aristóteles diz que...", que é o processo propriamente chamado de expositio do texto.

Em primeiro lugar, apesar de suas diferenças de estilo, os três autores se mantém bastante próximos ao texto. Mesmo afastando-se dele por meio de digressões ou de intervenções pessoais, eles têm o cuidado de seguir a ordem do texto. Isso é um sinal, na nossa opinião, do objetivo didático, 
comum aos três autores. Todos tem como objetivo desfazer a dificuldade do texto, explicando-o aos estudantes. De fato, Roberto escreveu o seu trabalho em um ambiente em que os textos lógicos de Aristóteles recentemente descobertos despertavam muito interesse mas onde eram escassos os mestres que os ensinavam, por causa de dificuldade destes. Alberto manifesta várias vezes a sua intenção de expor o conjunto da obra científica de Aristóteles para o entendimento da doutrina aristotélica, com conhecimento de sua lógica é fundamental, ele também se dedicou a produzir um comentário sobre essa parte também. Quanto a Tomás, o pedido dos mestres de artes para que este escrevesse a sua Expositio parece indicar que em Paris ainda não havia um trabalho que facilitasse o aprendizado desta obra (supondo que o comentário de Roberto tivesse circulado mais na Inglaterra e o de Alberto na Alemanha).

Quanto à doutrina, também os três comentários são muito parecidos, pelo menos neste ponto que é objeto de nossa pesquisa. Apresentam a necessidade do conhecimento prévio para que se dê o conhecimento científico, identificam os dois tipos (que é, e o que é dito) e a combinação de ambos; a consideração sobre a anterioridade temporal e lógica na relação entre o conhecimento das premissas e o conhecimento da conclusão e, finalmente, a consideração sobre o problema do Mênon. Quanto ao Mênon, o diálogo platônico citado por Aristóteles, não parece que nenhum dos três o conhecesse diretamente, embora todos o identifiquem como o diálogo de Platão que tem esse título por causa do nome do discípulo platônico; Roberto e Alberto se dão ao luxo de ir além e nos informam sobre a intenção inicial do texto platônico, que é investigar se a virtude pode ser ensinada e ambos citam o exemplo do senhor que perde o escravo e não o reconhece, embora Alberto atribua o exemplo a Agostinho.

Com relação às diferenças, o modo como eles dividem o texto é bastante característico de cada um, Roberto apresenta o texto na forma de uma sucessão de conclusões, embora divida o seu comentário em capítulos. Não há introdução geral, ele entra diretamente no texto, informando que o primeiro capítulo é uma introdução do próprio Aristóteles ao que 
se seguirá, na qual ele mostra, por redução ao absurdo que o ensino e aprendizado é possível (pois senão acontece a ambiguidade do Mênon). Embora não se demore muito neste ponto, é aqui que, a nosso ver estaria o ponto de maior tensão entre o ensino de Aristóteles e as convicções de seu comentador, pois Grosseteste lembra que, na verdade não é o mestre que ensina oralmente ou por escrito, mas é o mestre interior ou a luz interior que comanda o processo de auto aprendizado (em que medida isso é uma concessão à própria tese platônica exposta no Mênon, Roberto não se dá ao trabalho de discutir).

Alberto divide o texto e o apresenta na forma de tratados, que são subdivididos em capítulos. Já vimos que, nestes tratados ele se dá a liberdade de fazer amplas digressões e mobilizar o seu amplo conhecimento da filosofia. Os dois capítulos do tratado primeiro se apresentam, assim, como introdutórios ao próprio comentário.

Tomás divide escrupulosamente o texto e o apresenta em forma capítulos. Os capítulos do comentário coincidem, mas não sempre, com os capítulos do próprio texto aristotélico. Embora os capítulos não tenham título, o que parece dar unidade a ele é uma certa unidade de assunto. Assim, o capítulo primeiro dos Segundos Analíticos é comentado nos três primeiros capítulos do comentário, sendo o capítulo primeiro uma introdução geral ou proêmio (à maneira de Alberto), no qual, após fazer uma apresentação de conjunto da lógica aristotélica e estabelecer o lugar dos Segundos Analíticos no conjunto da obra, Aristóteles mostra que todo ensinamento e todo aprendizado intelectual se dá a partir de conhecimento prévio, no segundo capítulo define-se qual a natureza desse conhecimento prévio e no terceiro explica em que sentido o conhecimento da conclusão é anterior.

\section{Conclusão}

O trabalho que apresentamos até aqui pretende ser o início de uma comparação dos três comentários em sua íntegra, ao final do qual teremos 
condições de apresentar uma opinião a respeito do caráter geral do aristotelismo de cada um desses expositores. Neste sentido, apresentamos, a título de conclusão, as seguintes considerações a respeito da atitude tomista como comentador de Aristóteles.

Em primeiro lugar, dadas as diferenças que pudemos observar entre as três perspectivas, e supondo que Tomás tivesse conhecimento dos dois comentários latinos anteriores, parece que ele não estava satisfeito com a perspectiva de nenhum deles, razão plausível para levar a cabo a tarefa de expor o difícil texto dos Segundos Analíticos ${ }^{31}$. Ele segue rigorosamente o modelo parisiense ${ }^{32}$, dividindo e subdividindo o texto até o limite de suas linhas, afastando-se assim das paráfrases de Roberto e de Alberto nas quais, descontada a erudição, parece presente ainda uma mistura de platonismo ou neoplatonismo à exposição de Aristóteles, da qual aliás o próprio Tomás não está totalmente isento ${ }^{33}$. Embora se possa explicar esse fato pela conviç̧ão, compartilhada entre os três segundo a qual o que importa é expor a verdade e não o pensamento de Aristóteles (assim, se Aristóteles se afasta da verdade, pior para ele), é certo que há um esforço maior por parte de Tomás em seguir o texto mais estritamente; para tanto o seu método de divisão exaustiva é mais eficiente do que a paráfrase de Alberto ou a exposição por sequência de conclusões de Roberto.

Em segundo lugar, os comentários anteriores são valiosa fonte de informação que permitem a Tomás de Aquino entender o assunto em questão (mesmo que ele discorde da interpretação dada), diante

31 Como escreve Leo Elders (2009, p. 31): "todos sabemos quão difíceis de decifrar são as traduções latinas do texto de Aristóteles; por essa razão, uma apresentação clara do que Aristóteles ensinara deve ter sido muito bem vinda. Tomás propunha colocar os estudantes em contato direto com o texto, ao mesmo tempo em que fornecia um guia, ficando ele mesmo em segundo plano".

32 Na verdade, as exposições de Tomás parecem ser o próprio modelo do chamado comentário parisiense.

33 Esse ponto pretendemos investigar em futuros trabalhos sobre a comparação dos comentários. 
de um texto que, se não é lacunar, é bastante enigmático. Gauthier ${ }^{34}$ conta, quanto ao comentário ao capítulo 1 do texto aristotélico, 3 passagens em que Tomás se apoia no texto de Grosseteste e 7 passagens em que ele se apoia no texto de Alberto Magno. De resto, o texto aristotélico é, ainda hoje, singularmente impenetrável se não dispusermos das chaves de leitura que seus comentadores antigos e medievais nos legaram.

Com relação à estrutura dos comentários, notamos que os três seguem, na exposição, a ordem do texto aristotélico e procuram dar conta do conteúdo de toda a obra, o que parece evidenciar o seu propósito didático. Isto é, trata-se de uma tentativa de cobrir exaustivamente o conteúdo integral da desta obra aristotélica, diferentemente inclusive dos comentários modernos de Ross e de Pochat, que se concentram em alguns temas sem a obsessão de dar conta do texto todo.

O comentário de Tomás, sendo o mais novo dentre os três analisados parece dialogar com os anteriores, procurando incorporar o que ele pensa estar certo e evitar os possíveis erros, mas não de maneira explícita. Assim, ele apresenta, a maneira de Alberto Magno, um prólogo que enquadra a obra comentada na estrutura do corpus aristotélico e relaciona a estrutura da lógica, tal como arquitetada por Aristóteles, com a estrutura dos pró-

34 As passagens citadas por Gauthier são as seguintes: em I,2, 17-49 se apoia em Grosseteste, In Post I, 1, 46 - 49 e Alberto, Post. I, 1,4, p.14; em I,2, 108 se apoia Alberto, Post. I,1,4, p.12; em I,2, 17 -49 se apoia em Grosseteste, In Post I,1, 57 - 58; em I,2, 155 - 183 se apoia em Alberto, Post. I,1,5 p. 14 - 15; em I,2, 190 - 203 se apoia em Alberto, Post. I,1,5, p. 15; em I,3, 10 - 11 se apoia em Alberto, Post. I, 1,5, p.15b; em I,3, 37 - 39 se apoia em Grosseteste, In Post I, 1, 97 - 101 e Alberto, Post. I,1,5, p. 16 (é a parte em que se identifica o texto do Mênon, embora todos possam também depender, quanto a isso, do comentário de Temístio); em I,3, 64 - 68 se apoia em Alberto, Post. I,1,6, p.18 (identificação de Anaxágoras como fonte da doutrina da reminiscência platônica, este ponto, no entanto já aparecera em textos anteriores de Tomás, como o Comentário às Sentenças, o que não exclui, na verdade talvez até confirma, a influência de Alberto); Tomás de Aquino (1989) p. 10 - 16, notas. 
prios atos do intelecto e da razão. No decorrer da exposição, no entanto, ele se permite poucas intervenções, esforçando-se por apresentar o texto e ficar em segundo plano, como faz Roberto Grosseteste.

Com relação especificamente ao ponto da doutrina que tratamos nesta comunicação, qual seja, o tema do conhecimento anterior necessário à ciência e o problema do Mênon, notamos que, em sua apresentação, Tomás evita associar o conhecimento prévio de que necessitamos para atingir o conhecimento científico à iluminação divina, o que parecem fazer os outros dois comentadores.

\section{Referências}

ASHLEY, BENEDICT M. St. Albert and the Nature of Natural Science. In: Weisheipl, James A. (Ed.). Albertus Magnus and the Sciences - Commemorative Essays, Toronto: Pontifical Institute of Mediaeval Studies, 1980.

ALBERTI MAGNI, D. Opera Omnia, v. 2. Paris: Vives, 1890. Liber I e Liber II Posteriorum Analyticorum. Edição de Augusto Borgnet.

ELDERS, Leo. The aristotelian commentaries of St. Thomas Aquinas. In: . The Review of Metaphysics n. 63, p. 29 - 53, Set. 2009.

PEREIRA, Oswaldo Porchat. Ciência e dialética em Aristóteles. São Paulo: Editora da UNESP, 2001.

MCEVOY, James. Robert Grosseteste, New York: Oxford University Press, 2000.

OWENS, Joseph. Aquinas as an Aristotelian commentator. In: Saint Thomas Aquinas on the Existence of God: The Collected Papers of Joseph Owens. Albany: SUNY Press, 1980

GROSSETESTE, Robertus. Commentarius in Posteriorum Analyticorum Libros, Firenze: L.S. Olschki, 1981. Edição crítica e introdução de Pietro Rossi. 
ROSS, W. D. (Ed.). Aristotle's Prior and Posterior Analytics, New York: Oxford Universit Press, 2000.

TOMÁS DE AQUINO. Opera Omnia iussu Leonis XIII P.M. edita, Roma: Comissio leonina/ Librairie Philosophique J.Vrin, 1989. Editio altera retractata, cura et studio Fratrum Praedicatotum, volume I-2.

TORREL, J-P. Iniciação a Santo Tomás de Aquino, São Paulo: Loyola, 2004.

WEIJERS, OLGA. La Structure des commentaires philosophiques et la facultè des arts: quelques observations. In: ico nell'ocidente latino, Turnhout: Brepols, 2002.

WEISHEIPL, JAMES A. (Ed.). Albertus Magnus and the Sciences - Commemorative Essays, Toronto: Pontifical Institute of Mediaeval Studies, 1980.

. The life and works of St. Albert the Great. In: WEISHEIPL, James A. (Ed.). Albertus Magnus and the Sciences - Commemorative Essays, Toronto: Pontifical Institute of Mediaeval Studies, 1980.

Data de registro: $26 / 09 / 2015$

Data de aceite:26/03/2016 